\title{
Prevalence of Dental Fluorosis in Disabled Children and Young Adults in Kuwait
}

\author{
Maddi Shyama ${ }^{a}$ Sabiha A. Al-Mutawa ${ }^{a}$ Sisko Honkala ${ }^{b}$ \\ ${ }^{a}$ Oral Health Services, Ministry of Health and ${ }^{b}$ Faculty of Dentistry, Health Sciences Centre, Kuwait University, \\ Kuwait
}

\section{Key Words}

Fluorosis · Disabled · Children · Young adults

\begin{abstract}
Objective: The aim of this study was to determine the prevalence of dental fluorosis in disabled subjects attending the special needs schools in Kuwait. Methods: Eight hundred and thirty-two subjects (442 males, and 390 females) aged 3-29 years, who were visually or hearing impaired or who had physical or developmental disorders, were included in the study. The mean age of the subjects was 12.1 years. The subjects were examined for dental fluorosis using WHO criteria. Dental fluorosis was scored according to Dean's index. Results: None of the subjects had severe fluorosis; less than $1.0 \%$ of them showed moderate fluorosis; $0.7 \%$ had mild and $2.5 \%$ had very mild fluorosis. There were no subjects with fluorosis up to the age of 7 years, but the prevalence varied from 0 to $10 \%$ between 8 and 20 years and only 1 subject above 20 years of age had fluorosis. Non-Kuwaiti nationality was a significant risk factor for the occurrence of dental fluorosis ( $O R=2.4 ; p=0.027$ ). Conclusion: Fluorosis was less prevalent among these disabled subjects than had been reported among the healthy population in Kuwait.
\end{abstract}

\section{Introduction}

Dental fluorosis is a specific fluoride-induced disturbance of tooth formation in which enamel development is disrupted and hypomineralized [1]. The hypomineralization is due to chronic ingestion of excessive amounts of fluoride during the period of tooth development [2]. Fluorotic enamel has a characteristic appearance and usually can be distinguished from other enamel disturbances [1]. Endemic dental fluorosis appears in areas where drinking water naturally contains a high concentration of fluorides. Clinically, the condition is characterized by lusterless, opaque white patches or striations in enamel. In some cases the enamel is pitted and in many others the enamel is stained yellow to dark brown [3]. Fluorotic lesions are usually bilaterally symmetrical. The premolars and second molars are most frequently affected, followed by the upper incisors, while mandibular incisors are least affected [4].

The fluorosis studies undertaken in fluoridated and non-fluoridated areas have identified four major risk factors: use of fluoridated drinking water, fluoride supplements, fluoride toothpaste, and infant formulas before the age of 8 years [5]. The most important risk factor in determining fluorosis occurrence and severity is the total amount of fluoride consumed from all sources during the critical period of tooth development $[6,7]$.

\begin{tabular}{ll}
\hline KARGER & ( ) 2001 S. Karger AG, Basel \\
Fax +4161306 1234 & 1011-7571/01/0102-0093\$17.50/0 \\
$\begin{array}{l}\text { E-Mail karger@karger.ch } \\
\text { www.karger.com }\end{array}$ & $\begin{array}{l}\text { Accessible online at: } \\
\text { www.karger.com/journals/mpp }\end{array}$
\end{tabular}

Maddi Shyama

PO Box 419

Central Salmiya 22005 (Kuwait)

Tel./Fax +965 5641686

E-Mailmshyama@hotmail.com 
National surveys of children's oral health were carried out in Kuwait in 1982 [8] and in 1993 [9] among the normal population. The prevalence of dental fluorosis was found to be quite high although rarely severe. These surveys did not include the disabled population; hence the aim of the present study was to determine the prevalence of fluorosis in disabled subjects in Kuwait.

\section{Methods}

The study was carried out in the Hawally Governorate, the district where all the schools for special needs subjects were located in Kuwait in 1999. The target population comprised of all the subjects with sensory deficits, physical handicaps and developmental disorders. Since the population was small, all subjects were targeted. The survey sample comprised 832 children and young adults studying in the special needs schools $(n=10)$ in the governorate. They suffered from the following conditions: blindness (65), deafness-muteness (312), Down syndrome (184), and physical disabilities (cerebral palsy, arthritis, congenital deformities, poliomyelitis, spina bifida) (271). No other handicapping condition was recorded and the individuals were classified according to their main reason for disability. Their ages ranged from 3 to 29 years, the mean age being 12.1 years. Kuwaitis represented $75 \%$ and non-Kuwaitis $25 \%$ of the sample. Females represented $47 \%$ and males $53 \%$. The distribution of the study population by disabling condition and age is shown in table 1 .

The informed consent of parents and school authorities was obtained before including the individuals in the study. The following demographic variables were registered for each subject: residence, school, gender, age at last birthday, and nationality (Kuwaiti, nonKuwaiti). These demographic data were recorded prior to the dental examination.

All the subjects were examined for dental fluorosis by two examiners who had been calibrated. The dental examinations were carried out in the school medical room or classroom under natural daylight according to the WHO criteria [4] with the aid of plain mouth mirror. Individuals were placed on a desk lying down or an examination couch in the supine position, unless they were confined to a wheelchair. Dental fluorosis was scored according to Dean's classification [10]. The scoring was made on the basis of the two most affected teeth. If the two teeth were not equally affected, the score for the less affected of the two was recorded. The teeth were not especially cleaned or dried. Ten percent of the subjects were re-examined to test intra- and inter-examiner reproducibility. Special concern was put under differential diagnosis of developmental disturbances of enamel lesions from fluorosis, e.g. enamel opacities, hypoplasia and other defects appearing non-symmetrically were not recorded as fluorosis [4].

\section{Statistical Methods}

The data were analyzed using the statistical software SPSS, Windows 9.0. Chi-square tests were used to test differences in frequencies between groups and for testing the associations of the variables, namely age groups, gender, nationality, disabling condition with the prevalence of fluorosis. In the analyses, Dean's fluorosis scores were combined into two categories, $0+1$ (normal and questionable) and $2+3+4+5$ (very mild, mild, moderate and severe). In bivariate
Table 1. Distribution of the study population by disabling condition and age (years)

\begin{tabular}{lrrr}
\hline Disabling condition & $\mathrm{n}$ & \multicolumn{1}{l}{$\%$} & Age, range \\
\hline Blind & 65 & 7.8 & $4-19$ \\
Hearing impaired & 312 & 37.5 & $4-22$ \\
Physical handicap & 271 & 32.6 & $3-29$ \\
Down syndrome & 184 & 22.1 & $5-22$ \\
\hline Total & 832 & 100.0 & $3-29$ \\
\hline
\end{tabular}

analysis, age was used as a continuous variable, but in the logistic regression it was dichotomised by regrouping it into 3-8 and 9-29 years. Multivariate analysis (logistic regression) was used to test the association of various socio-demographic and other factors for the occurrence of fluorosis. Odds ratios (OR) and their confidence intervals $(95 \% \mathrm{CI})$ were estimated for fluorosis. The following explanatory factors were included in the logistic regression model: recorded age, gender, nationality and disabling condition.

\section{Results}

Intra- and inter-examiner agreement for Dean's index was found to be $80 \%$. None of the subjects had severe fluorosis; less than $1.0 \%$ of them showed moderate fluorosis; $0.7 \%$ mild fluorosis; $2.5 \%$ very mild fluorosis and $5.8 \%$ questionable fluorosis. There was no dental fluorosis among subjects up to the age of 7 years, but the prevalence varied from 0 to $10 \%$ between 8 and 20 years (fig. 1). Among children over 20 years $(n=14)$ there was only 1 subject with fluorosis. There was no association between fluorosis and age in bivariate analysis $(\mathrm{p}=$ 0.094). Non-Kuwaitis had a higher prevalence of fluorosis $(6.8 \%)$ than Kuwaitis $(2.4 \% ; \mathrm{p}=0.004, \mathrm{OR}=3.0)$ in bivariate analyses. There were no differences in the prevalence of dental fluorosis between the disabling conditions $(p=0.275)$ (table 2$)$ and gender $(p=0.513)$. When the simultaneous associations of different explanatory variables were studied using a logistic regression model for the occurrence of fluorosis, being of non-Kuwaiti nationality was the only significant risk factor for the occurrence of fluorosis $(\mathrm{OR}=2.4 ; \mathrm{p}=0.027)$ (table 3$)$.

\section{Discussion}

Dean's index was used for scoring dental fluorosis because of its simplicity and its ability to make comparisons with numerous earlier studies [11]. However, several 
Fig. 1. Prevalence (\%) of dental fluorosis in the sample (n) according to age.

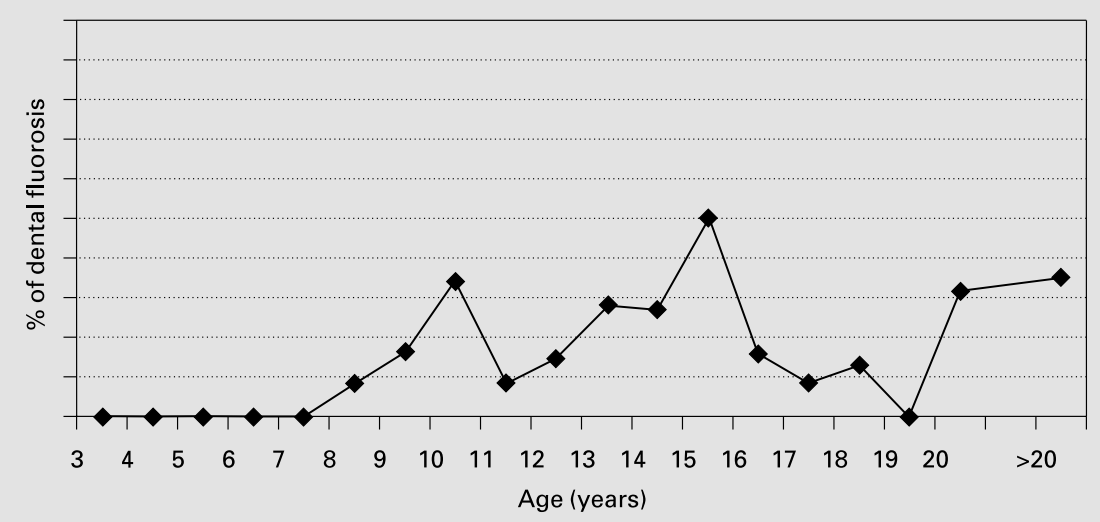

\begin{tabular}{llllll} 
Disabling condition & $\begin{array}{l}\text { No fluorosis } \\
(0)\end{array}$ & $\begin{array}{l}\text { Questionable } \\
(1)\end{array}$ & $\begin{array}{l}\text { Very mild } \\
(2)\end{array}$ & $\begin{array}{l}\text { Mild } \\
(3)\end{array}$ & $\begin{array}{l}\text { Moderate } \\
(4)\end{array}$ \\
\hline Blind (65) & 87.7 & 9.2 & 1.5 & 1.5 & 0.0 \\
Hearing impaired (312) & 88.5 & 6.7 & 3.2 & 1.3 & 0.3 \\
Physical handicap (271) & 92.3 & 5.9 & 1.1 & 0.4 & 0.4 \\
Down syndrome (184) & 93.5 & 2.7 & 3.8 & 0.0 & 0.0 \\
\hline Average & 90.5 & 6.1 & 2.4 & 0.8 & 0.2
\end{tabular}

Table 2. Percentage distribution of sample (n) according to the fluorosis score by disabling condition
Table 3. Estimated odds ratios (OR) and p values for fluorosis

\begin{tabular}{lll}
\hline & OR & $\begin{array}{l}\text { Statistical } \\
\text { significance (p) }\end{array}$ \\
\hline $\begin{array}{l}\text { Disabling condition } \\
\text { Blind (ref.) }\end{array}$ & 1.0 & - \\
$\quad$ Hearing impaired & 1.3 & 0.748 \\
$\quad$ Physical handicap & 0.8 & 0.747 \\
$\quad$ Down syndrome & 1.2 & 0.812 \\
\hline Gender & & \\
$\quad$ Male (ref.) & 1.0 & - \\
$\quad$ Female & 1.2 & 0.675 \\
\hline Nationality & & \\
$\quad$ Kuwaiti (ref.) & 1.0 & - \\
$\quad$ Non-Kuwaiti & 2.4 & 0.027 \\
\hline Age & & - \\
3-8 (ref.) & 1.0 & 0.067 \\
9-29 & 6.5 & \\
\hline
\end{tabular}

Med Principles Pract 2001;10:93-97 
studies $[8,9]$. The prevalence of fluorosis (mild to moderate) among normal children ranged between 18 and 27\% in 1982 , reducing consistently with decreasing age to $2 \%$ among 6-year-olds [8]. However, in 1993 much lower prevalence values were reported: $6 \%$ among 12 - and 15 year-olds and $1 \%$ among 7-year-olds [9]. In the disabled subjects, none of them had severe fluorosis; less than $1.0 \%$ showed moderate fluorosis; $0.7 \%$ had mild and $2.5 \%$ had very mild fluorosis. It was expected that the prevalence of fluorosis would have been higher among this special group of children as they have other associated developmental defects and abnormalities. However, the disabled populations in these special needs schools have not been covered by the systematic oral health programs that cover the normal children and devoid of fluoride supplements which might be one reason for lower prevalence of fluorosis figures among disabled. The cause of fluorosis in Kuwait is not likely to be related to the water fluoridation that was operational between 1974 and 1980 because the 12-year-old children who had fluorosis were born 2 years after water fluoridation was discontinued. It is well known that dental fluorosis can result from chronic ingestion of excessive amounts of fluoride during early tooth development [15]. The use of fluoride supplements has been shown to increase the risk of fluorosis and when combined with other sources of fluoride (dentifrices, fluoridated water, fluoride in foods) and the risk of developing fluorosis, including moderate levels, increases [16]. However, the bulk of the fluorosis seen when young children use supplements is of mildest varieties [17]. There has been special concern on the negative effects of fluorides especially recently, when several fluoride methods [18] are used simultaneously. A recent systematic review [19] pointed out 'the cosmetically unacceptable fluorosis'. Highly significant associations between estimated fluoride ingestion from toothpaste and dental fluorosis have been reported [20].

The finding that being of non-Kuwaiti nationality was a significant risk factor for the occurrence of fluorosis both in bivariate and multivariate analyses suggests that some non-Kuwaitis probably came from countries with some endemic fluorosis areas. Although both primary and permanent teeth may be affected by fluorosis, under uniform conditions of fluoride availability, fluorosis tends to be greater in the permanent teeth [15]. This disparity may be due to the fact that much of the mineralization of primary teeth occurs before birth, the placenta serving as a barrier to the transfer of high concentrations of plasma fluoride from a pregnant mother to her developing fetus, thus controlling to a certain extent the delivery of fluoride to the developing primary dentition [15]. However, it is now quite well established that fluoride enters the prenatal deciduous enamel and it is transferred through the placenta and is distributed to the fetus [21]. Other reasons may be that the period of enamel formation for primary teeth is shorter than for permanent teeth and that the enamel of primary teeth is thinner than that of permanent teeth [15].

\section{Conclusion}

The prevalence of dental fluorosis among disabled subjects in Kuwait is very low. Being of non-Kuwaiti nationality was the only factor associated with fluorosis.

\section{Acknowledgements}

This study was supported by the Ministry of Health, Kuwait. We would like to thank Dr. R. Morris, consultant of the Ministry of Health, for his advice and guidance in planning this study and in calibration of the examiners. We are grateful to Dr. E. Honkala and Dr. T. Sugathan for the valuable guidance and suggestions for this study. Our warmest thanks are to the school authorities, the teachers and all the children and adults who participated in this study. 


\section{References}

1 Fejerskov O, Manji F, Baelum V: The nature and mechanism of dental fluorosis in man. $\mathrm{J}$ Dent Res 1990;69:692-700.

2 Murray JJ, Rugg-Gunn JA, Jenkins GN: Epidemiology and measurement of dental fluorosis; in Fluorides in Caries Prevention, ed 3. London, Butterworth-Heinmann/University Press Cambridge, 1991, pp 222-261.

3 Murray JJ: Appropriate Use of Fluorides for Human Health. Geneva, WHO, 1986.

4 World Health Organization: Oral Health Surveys: Basic Methods, ed 4. Geneva, WHO, 1997.

5 Mascarenhas AK: Risk factors for dental fluorosis: A review of the recent literature. Pediatr Dent 2000;22:269-277.

6 Dean HT, Arnold FA, Elvove E: Domestic water and dental caries V. Additional studies of the relation of fluoride domestic waters to dental caries experience in 4,425 white children aged 12-14 years in 13 cities in 4 states. Public Health Rep 1942;57:1155-1179.

7 Richards A, Likimani S, Baelum V, Fejerskov $\mathrm{O}$ : Fluoride concentrations in unerupted fluorotic human enamel. Caries Res 1992;26:328332.

8 Glass RL: Kuwait National Dental Survey, Part 1: The Oral Health of School Children in Kuwait 1982. State of Kuwait, Ministry of Health, 1983.
9 Vigild M, Skougaard M, Hadi RA, Al Za'abi F, Al-Yasseen I: Dental caries and dental fluorosis among 4-, 6-, 12-, and 15-year-old children in kindergartens and public schools in Kuwait. Community Dent Health 1996;13:47-50.

10 Dean HT: The investigation of physiological effects by the epidemiological method; in Moulton FR (ed): Fluoride and Dental Health. Washington, American Association for the Advancement of Science, 1942, Publ No 19, pp 23-31.

11 Kumar JV, Swango PA, Opima PN, Green EL: Dean's fluorosis index: An assessment of examiner reliability. J Public Health Dent 1999;59: 269-274.

12 Thylstrup A, Fejerskov O: Clinical appearance of dental fluorosis in permanent teeth in relation to histologic changes. Community Dent Oral Epidemiol 1978;16:315-328.

13 Fejerskov O, Baelum V, Manji F, Moller IJ: Dental Fluorosis: A Handbook for Health Workers. Copenhagen, Munksgaard, 1988.

14 Clarkson J: Review of terminology, classifications and indices of developmental defects of enamel. Adv Dent Res 1989;3:104-109.
15 Murray JJ, Rugg-Gunn AJ, Jenkins GN: Fluorides in Caries Prevention, ed 3. Oxford, Oxford University Press, 1991, p 222.

16 Ismail AI: Fluoride supplements: Current effectiveness, side effects, and recommendations. Community Dent Oral Epidemiol 1994; 22:164-172.

17 Burt BA: The case for eliminating the use of dietary fluoride supplements for young children. J Public Health Dent 1999;59:269-274.

18 Riordan PJ: Perceptions of dental fluorosis. J Dent Res 1993;72:1268-1274.

19 Tabari ED, Ellwood R, Rugg-Gunn AJ, Evans DJ, Davies RM: Dental fluorosis in permanent incisor teeth in relation to water fluoridation, social deprivation and toothpaste use in infancy. Br Dent J 2000;189:2 16-220.

20 Rock WP, Sabieha AM: The relationship between reported toothpaste use in infancy and fluorosis of permanent incisors. Br Dent $\mathrm{J}$ 1997; 183:165-170.

21 Toyama Y, Nakagaki H, Kato S, Huang S, Mizutani Y, Kojima S, Toyama A, Ohno N, Tsuchiya T, Kirkham J, Robinson C: Fluoride concentrations at and near the neonatal line in human deciduous tooth enamel obtained from a naturally fluoridated and a non-fluoridated area. Arch Oral Biol 2001;46:147-153. 